\title{
Analisis Sentimen Pada Review Objek Wisata Dunia Fantasi menggunakan Algoritma K-Nearest Neighbor (K-NN)
}

\author{
Retno Sari \\ Teknik Informatika, STMIK Nusa Mandiri \\ Indonesia \\ E-mail:retno.rnr@nusamandiri.ac.id
}

\begin{abstract}
Reviews of tourist attractions make it easier for other visitors to know the state of the place and become input for other visitors. Sentiment analysis is needed to make the best decision. This study aims to determine the accuracy of sentiment analysis using the K-Nearest Neighbor algorithm, which reviews using Indonesian language texts. The advantages of $k-N N$ have a simple principle, working based on the shortest distance from the test sample and training sample. In this research, preprocessing used is tokenize, stopword filter and bi-gram. The data used consisted of 50 positive reviews and 50 negative reviews. Experiments have been carried out by changing the value of $k$ and obtained the greatest accuracy with a value of $k=7$ with an accuracy of 77.01, precission 92.38, recall 61.56 and AUC value of 0.894 .
\end{abstract}

Keywords: sentiment analysis;Review of attractions; $k-N N$

Abstrak

Review mengenai tempat wisata memudahkan pengunjung lain untuk mengetahui keadaan tempat tersebut dan menjadi masukan untuk pengunjung lain. Analisis sentimen diperlukan untuk mengambil keputusan yang terbaik. Penelitian ini bertujuan untuk mengetahui akurasi analisis sentimen dengan menggunakan algoritma K-Nearest Neighbor yang mana review menggunakan teks berbahasa Indonesia. Kelebihan k-NN memiliki prinsip sederhana, bekerja berdasarkan jarak terpendek dari sampel uji dan sampel latih. Pada penelitian ini preprocessing yang digunakan yaitu tokenize, filter stopword dan bi-gram. Data yang digunakan terdiri dari 50 review positif dan 50 review negative. Eksperimen telah dilakukan dengan mengubah nilai $\mathrm{k}$ dan didapat akurasi yang terbesar dengan nilai $\mathrm{k}=7$ dengan akurasi 77.01 , precission 92.38 , recall 61.56 dan nilai AUC 0.894.

Kata kunci : analisis sentiment; review objek wisata; k-NN

\section{Introduction}

Banyaknya review mengenai tempat wisata yang telah dikunjungi, memudahkan pengunjung lain yang ingin berkunjung ke tempat tersebut mengetahui keadaan di tempat tersebut dan menjadikan masukan untuk pengunjung lain untuk memutuskan ke tempat tersebut atau tidak. 
Pengelolaan analisis sentimen menjadi suatu informasi untuk sesama pengunjung ataupun pelaku bisnis, untuk pelaku bisnis informasi yang didapat sangat berguna untuk menjalankan bisnisnya (Fitrianti et al., 2019).

Analisis sentimen merupakan penilaian publik, penilaian mengenai kesukaan atau ketidaksukaan (Romadloni et al., 2019). Tujuan dari teks mining adalah memproses unstructured data (tekstual) guna dicari pola makna serta ditindaklanjuti dengan pengambilan keputusan yang terbaik (Ipmawati et al., 2017).

Terdapat penelitian mengenai analisis sentimen sebelumnya menggunakan algoritma K-Nearest Neighbor (K-NN). Penelitian sebelumnya yaitu penerapan algoritma K-Nearest Neighbor pada sentimen review agen travel (Ernawati \& Wati, 2018), Analisis sentimen kurikulum 2013 pada Twitter menggunakan Ensemble Feature dan metode K-Nearest Neighbor (Irfan et al., 2018).

Algoritma K-Nearest Neighbor (K-NN) merupakan metode lazy learning dimana tidak ada model yang dipelajari dari data testing, jadi hanya belajar dari contoh uji harus diklasifikasikan. Algoritma K-Nearest Neighbor (K-NN) bertujuan untuk mengklasifikasikan objek berdasarkan atribut dan data training (Salam et al., 2018).
Dari hasil penelitian sebelumya yang berjudul penerapan algoritma K-Nearest Neighbor pada sentimen review agen travel didapatkan akurasi sebesar $87.00 \%$, pada penelitian tersebut menggunakan bahasa Inggris dengan sentiment fast, good, great, bad, cencel dan wait (Ernawati \& Wati, 2018) .

Penelitian dengan judul analisis sentimen pada review objek wisata dunia fantasi menggunakan algoritma K-Nearest Neighbor bertujuan untuk mengetahui akurasi yang dihasilkan.

\section{Materials and Methods}

\subsection{Materials}

\subsubsection{Text Mining}

Teks merupakan sesuatu yang umum dalam melakukan pertukaran informasi. Syarat umu data dan teks mining adalah informasi yang diambil dan dapat menjadi data yang berguna. Teks mining merupakan proses menganalisa teks untuk menjadi informasi yang berguna untuk tujuan tertentu. Informasi yang diambil harus jelas dan eksplisit, karena teks mining merubah menjadi bentuk yang dapat digunakan oleh komputer atau orang yang tidak memiliki waktu untuk membaca full teks (Bramer, 2007).

Metode teks mining melihat format dokumen dan presentasi standar untuk 
belajar yaitu format XML yang digunakan untuk dokumen (M.Weiss et al., 2010).

\subsubsection{Analisis Sentimen}

Analisis sentimen menentukan terhadap komentar mengenai permasalahan, apakah masalah tersebut memiliki kecenderungan positif atau negatif dan dapat dijadikan acuan untuk meningkatkan pelayanan atau kualitas produk (Nurjanah et al., 2017).

Sentimen analisis adalah riset komputasional dari opini, sentimen dan emosi yang di ekspresikan secara tekstual (Zulfa \& Winarko, 2017).

Analisis sentimen merupakan penelitian dalam bentuk analisis, mengenai opini dan emosi banyak orang(Pravina et al., 2019).

\subsubsection{K- Nearest Neighbor}

Metode K-Nearest Neighbor (k-NN) pertama kali di perkenalkan awal tahun 1960. Metode ini bekerja intensif ketika diberikan data training yang besar dan tidak populer sampai dengan tahun 1960. Ketika tekin komputasi sedang berkembang (Han \& Kamber, 2006).

Metode k-NN merupakan model supervised learning yang mana database populasi yang digunakan diidentifikasi terlebih dahulu ke dalam kelas tertentu (Nugraha et al., 2014).

k-NN memiliki prinsip sederhana, bekerja berdasarkan jarak terpendek dari sampel uji ke sampel latih. Sedangkan kekurangan dari k-NN yaitu computational cost dan sensitif terhadap derau dan input yang tidak sesuai (Budianto et al., 2018).

\subsubsection{Teks Preprocessing}

Teks preprocessing merupakan tahap awal dari text mining, proses ini untuk mempersiapkan data (Rustiana \& Rahayu, 2017).

\subsection{Methods}

Metode yang digunakan pada penelitian ini merupakan metode penelitian eksperimen, dengan tahapan sebagai berikut:

\section{a. Pengumpulan Data}

Penulis mengambil data dari situs review www.tripadvisor.com. Data yang diambil terdiri dari 50 review positif dan 50 review negative.

b. Pengolahan Awal Data

Preprocessing pada dataset yang dilakukan yaitu:

1) Tokenize

Tokenize merupakan tahap preprocessing dengan menghilangkan tanda baca maupun simbol apapun yang bukan huruf.

2) Filter Stopword

Pada tahap filter stopword membuang kata-kata berupa kata sambung, 
imbuhan, akhiran. Seperti kata “dari”,"yang”,"di”, dan “ke”.

3) N-gram

Pada tahap ini dilakukan pemotongan karakter dengan bi-gram yaitu pemotongan string sebanyak 2 bagian.

c. Metode yang digunakan

Pada penelitian ini menggunakan metode K-Nearest Neighbor (k-NN) untuk mengetahui akurasi yang dihasilkan.

d. Eksperimen dan Pengujian Metode

Eksperimen pada penelitian ini menggunakan Rapid Miner 5 dalam pengolahan data.

e. Evaluasi dan Validasi Hasil

Validasi dilakukan menggunakan fold cross validation, untuk melakukan pengukuran akurasi menggunakan confusion matrix dan kurva ROC untuk mengukur nilai AUC.

Berikut adalah gambar model dari penelitian ini:

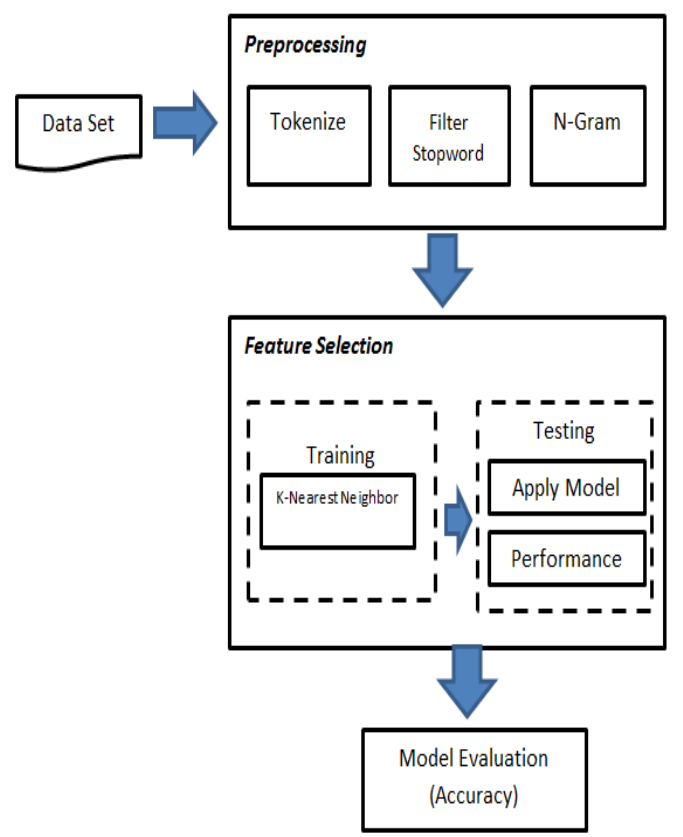

Gambar 1. Model Penelitian

\section{Results and Discussion}

Pada penelitian ini menggunakan data dari www.tripadvisor.com yang terdiri dari 50 data review positif dan 50 data review negative dengan teks berbahasa Indonesia. Data review tersebut dikelompokkan ke dalam folder positif untuk review positif dan dikelompokkan ke dalam folder negative untuk review negative.

Proses pengolahan awal terdiri dari proses tokenize, filter stopword dan n-gram. Pada proses tokenize semua review dihilangkan tanda baca maupun simbol apapun yang bukan huruf. Sehingga membentuk kumpulan kata yang memiliki arti. Pada tabel 1 dapat dilihat hasil dari proses tokenize. 
Tabel 1. Hasil Proses Tokenize

Review Tokenize

\begin{tabular}{|c|c|}
\hline $\begin{array}{lr}\text { Sangat } & \text { kecewa krn } \\
\text { ada } & \text { beberapa }\end{array}$ & $\begin{array}{lr}\text { Sangat } & \text { kecewa krn } \\
\text { ada } & \text { beberapa }\end{array}$ \\
\hline $\begin{array}{l}\text { wahana yg tdk } \\
\text { beroperasi }\end{array}$ & $\begin{array}{l}\text { wahana yg tdk } \\
\text { beroperasi }\end{array}$ \\
\hline sedangkan & sedangkan \\
\hline tersebut & tersebut \\
\hline diminati & diminati pengunjung \\
\hline pengunjung... & dan menjadi wahana \\
\hline menjadi & wahana \\
\hline wahana & antriannya \\
\hline antriannya & panjang \\
\hline anj & \\
\hline
\end{tabular}

Proses pengolahan data kedua yaitu

filter stopword. Pada proses ini membuang kata-kata berupa kata sambung, imbuhan, akhiran. Pada tabel 2 dapat dilihat hasil dari proses filter stopword.

Tabel 2. Hasil Proses Filter Stopword Review Filter Stopword

\begin{tabular}{lrrrr}
\hline \multicolumn{1}{l}{ Sangat } & kecewa krn & kecewa krn wahana \\
ada & beberapa & yg tdk & beroperasi \\
wahana & yg & tdk & wahana & diminati \\
beroperasi & & pengunjung & wahana \\
sedangkan & wahana & wahana & yg \\
tersebut & sangat & antriannya & \\
diminati & & & \\
pengunjung... & dan & \\
menjadi wahana- & \\
wahana yg lain & \\
\hline
\end{tabular}

antriannya sampai

panjang...

Proses pengolahan data yang terakhir yaitu n-gram. Pada proses ini dilakukan pemotongan karakter dengan bigram yaitu pemotongan string sebanyak 2 bagian. Pada tabel 3 dapat dilihat dari proses n-gram.

Tabel 3. Hasil Proses N-gram

Review Bigram

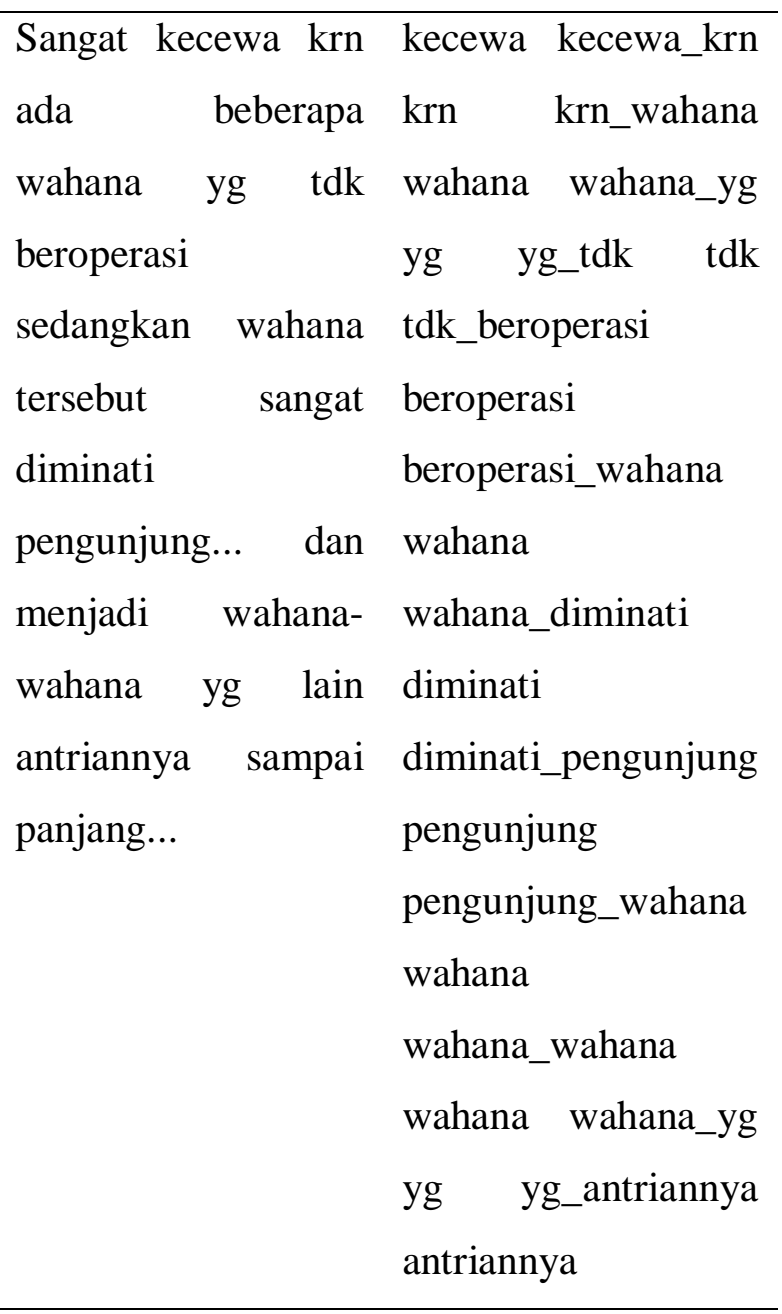


Pada penelitian ini pengujian dilakukan dengan model $k$ fold cross validation dimana proses ini membagi data secara acak kedalam k bagian. Proses pengujian dimulai dari pembentukkan model dengan data pada bagian pertama. Setelah dilakukan training dan testing maka dapat di ukur akurasinya.

Pengujian metode pada algoritma $\mathrm{K}$ Nearest Neighbor. Berikut adalah hasil dari eksperimen pengujian metode $\mathrm{K}$-Nearest Neighbor dengan fold cross validation.

Tabel 4. Nilai Akurasi pada K Nearest Neighbor

\begin{tabular}{ccccc}
\hline $\begin{array}{c}\text { Nilai } \\
\text { K }\end{array}$ & Accuracy & Precission & Recall & AUC \\
\hline 1 & 71.88 & 71.13 & 77.88 & 0.927 \\
\hline 2 & 64.77 & 74.44 & 52.05 & 0.868 \\
\hline 3 & 70.77 & 73.87 & 67.86 & 0.877 \\
\hline 4 & 75.92 & 91.67 & 58.07 & 0.875 \\
\hline 5 & 73.84 & 78.45 & 65.48 & 0.881 \\
\hline 6 & 74.94 & 89.52 & 57.84 & 0.894 \\
\hline $\mathbf{7}$ & $\mathbf{7 7 . 0 1}$ & $\mathbf{9 2 . 3 8}$ & $\mathbf{6 1 . 5 6}$ & $\mathbf{0 . 8 9 4}$ \\
\hline 8 & 73.56 & 86.25 & 58.57 & 0.894 \\
\hline 9 & 76.09 & 89.81 & 59.63 & 0.910 \\
\hline 10 & 76.00 & 91.00 & 60.00 & 0.912 \\
\hline
\end{tabular}

Berdasarkan tabel akurasi dengan KNearest Neighbor dengan mengubah nilai K. Pada tabel diatas dapat dilihat akurasi yang nilai $\mathrm{K}$ nya 7 memiliki akurasi yang paling besar yaitu $77.01 \%$.

Confusion matrix dengan menggunakan algoritma $K$-Nearest Neighbor dapat dilihat dari tabel 5.
Tabel 5. Confusion Matrix K-Nearest Neighbor

\begin{tabular}{lcc}
\hline \multicolumn{3}{c}{ Accuracy $:$ 77.01\%+/-7.00\%(mikro:77.00\%) } \\
\hline & $\begin{array}{c}\text { True } \\
\text { negative }\end{array}$ & True positif \\
\hline $\begin{array}{l}\text { Pred } \\
\text { negative }\end{array}$ & 46 & 19 \\
\hline Pred positif & 4 & 31 \\
\hline
\end{tabular}

Grafik ROC dari eksperimen menggunakan K-Nearest Neighbor dapat dilihat pada gambar 2 .

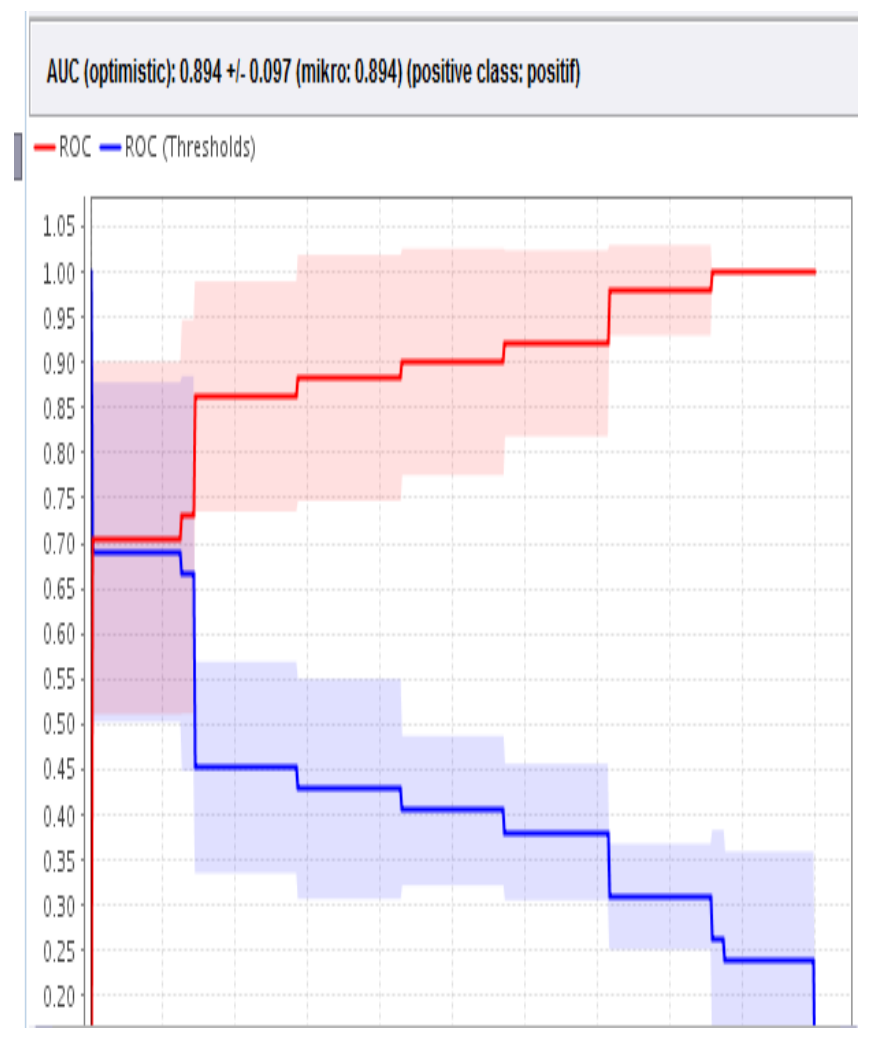

Gambar 2. Grafik ROC K-Nearest Neighbor

\section{Conclusions}

Pada penelitian ini review taman rekreasi dunia fantasi menggunakan KNearest Neighbor dengan teks berbahasa 
Indonesia menghasilkan akurasi sebesar $77.01 \%$ dengan nilai $\mathrm{K} 7$ menggunkan 10 fold cross validation.

\section{References}

Bramer, M. (2007). Principles of Data Mining. Springer.

Budianto, A., Maryono, D., \& Ariyuana, R. (2018). Perbandingan K-Nearest Neighbor (KNN) Dan Support Vector Machine (SVM) Dalam Pengenalan Karakter Plat Kendaraan Bermotor. Jurnal Ilmiah Pendidikan Teknik Kejuruan (JIPTEK), 11(1), 42-52. https://doi.org/10.20961/jiptek.v11i1.2 1088

Ernawati, S., \& Wati, R. (2018). Penerapan Algoritma K-Nearest Neighbors Pada Analisis Sentimen Review Agen Travel. Jurnal Khatulistiwa Informatika, VI(1), 64-69.

Fitrianti, R. P., Kurniawati, A., \& Agusten, D. (2019). Terhadap Analisis Sentimen Review Restoran Dengan Teks Bahasa Indonesia. Seminar Nasional Aplikasi Teknologi Informasi (SNATi) 2019, $27-32$.

Han, J., \& Kamber, M. (2006). Data Mining Concepts dan Technique. Elsevier.

Ipmawati, J., Kusrini, \& Taufiq Luthfi, E. (2017). Komparasi Teknik Klasifikasi
Teks Mining Pada Analisis Sentimen. Indonesian Journal on Networking and Security, 6(1), 28-36.

Irfan, M. R., Fauzi, M. A., \& Tibyani. (2018). Analisis Sentimen Kurikulum 2013 pada Twitter menggunakan Ensemble Feature dan Metode KNearest Neighbor. Jurnal Pengembangan Teknologi Informasi Dan Ilmu Komputer, 2(9), 3006-3014. http://j-ptiik.ub.ac.id

M.Weiss, S., Indurkhya, N., \& Zhang, T. (2010). Texts in Computer Science Fundamentals of Predictive Text Mining. Springer.

Nugraha, K. A., Hapsari, W., \& Haryono, N. A. (2014). Analisis Tekstur Pada Citra Motif Batik Untuk Klasifikasi KNN. Informatika, 10(2), 135-140.

Nurjanah, W. E., Perdana, R. S., \& Fauzi, M. A. (2017). Analisis Sentimen Terhadap Tayangan Televisi Berdasarkan Opini Masyarakat pada Media Sosial Twitter menggunakan Metode K-Nearest Neighbor dan Pembobotan Jumlah Retweet. Jurnal Pengembangan Teknologi Informasi Dan Ilmu Komputer (J-PTIIK) Universitas Brawijaya, 1(12), 17501757.

https://doi.org/10.1074/jbc.M20949820 
0

Pravina, A. M., Cholissodin, I., \& Adikara, P. P. (2019). Analisis Sentimen Tentang Opini Maskapai Penerbangan pada Dokumen Twitter Menggunakan Algoritme Support Vector Machine ( SVM ). Jurnal Pengembangan Teknologi Informasi Dan Ilmu Komputer (J-PTIIK) Universitas Brawijaya, 3(3), 2789-2797.

Romadloni, N. T., Santoso, I., \& Budilaksono,

S. (2019).

PERBANDINGAN METODE NAIVE BAYES ，KNN DAN DECISION TREE TERHADAP ANALISIS SENTIMEN TRANSPORTASI KRL. Jurnal IKRA-ITH Informatika, 3(2), 19.

Rustiana, D., \& Rahayu, N. (2017). Analisis Sentimen Pasar Otomotif Mobil: Tweet Twitter Menggunakan Naïve Bayes.
Simetris: Jurnal Teknik Mesin, Elektro Dan Ilmu Komputer, 8(1), 113-120. https://doi.org/10.24176/simet.v8i1.84 1

Salam, A., Zeniarja, J., Septiyan, R., Khasanah, U., Studi, P., Informatika, T., Komputer, F. I., Nuswantoro, U. D., \& Analysis, S. (2018). ANALISIS SENTIMEN DATA KOMENTAR SOSIAL MEDIA FACEBOOK DENGAN K-NEAREST NEIGHBOR ( STUDI KASUS PADA AKUN JASA. SINTAK 2018, 480-486.

Zulfa, I., \& Winarko, E. (2017). Sentimen Analisis Tweet Berbahasa Indonesia Dengan Deep Belief Network. IJCCS (Indonesian Journal of Computing and Cybernetics Systems), 11(2), 187. https://doi.org/10.22146/ijccs.24716 